ЮРИДИЧЕСКИЕ НАУКИ

УДК 349.6

ПРОБЛЕМЫ ОХРАНЫ ДАЛЬНЕВОСТОЧНЫХ ЛЕСОВ

DOI: $10.31618 / E S U .2413-9335.2021 .1 .90 .1449$

Шелеметьева Е.В.

Преподаватель кафедры государственно-правовых

и гражданско-правовых дисииилин,

ВФ ФГКОУ ВО «ДВЮИ МВД России».

PROBLEMS OF PROTECTION OF FAR EASTERN FORESTS

\author{
Shelemetyeva E.V. \\ Lecturer at the Department of State Legal \\ and Civil Law Disciplines Far Eastern Law Institute of \\ the Ministry of the Internal of the Russian Federation
}

\begin{abstract}
АННОТАЦИЯ
В статье анализируются имеющиеся проблемы, которые связаны с полноценной охраной всех дальневосточных лесов, а также указываются нормы права, которые регулируют рассматриваемый вопрос. Изучаются имеющиеся у страны возможности для введения определенного дистанционного мониторинга, как решения рассматриваемых проблем, кроме этого проводится краткий анализ введения данной меры в иных районах России.
\end{abstract}

The article analyzes the existing problems that are associated with the full protection of all Far Eastern forests, and also specifies the legal norms that regulate the issue under consideration. The possibilities available to the country for conducting certain remote monitoring as a solution to the problems under consideration are being studied, in addition, a brief analysis of the introduction of this measure in other regions of Russia is being conducted.

Ключевые слова: лесной фонд, Дальневосточный федеральный округ, дистанционный мониторинг, проблема, природа, незаконная рубка.

Keywords: forest fund, Far Eastern Federal District, remote monitoringю, problem, nature, illegal logging.

Природа является важной частью жизни каждого человека, которая зависит от непрерывного функционирования природных систем и ее элементов. Страны всего мира достаточно давно имеют общее мнение, касающееся того, что лес является наиболее ценным и значимым природным ресурсом, имеющимся на всей нашей планете. В случае возникновения, каких-либо катаклизм или же сильных пожаров, а также значительных воздействий на имеющиеся в стране лесные массивы в итоге его реально в полной мере воссоздать. При этом нужно понимать, что для воссоздания лесов необходим большой промежуток времени, а возможно и десятилетия. На основании данного фактора следует в полной мере оберегать лес от незаконной вырубки, а также грамотно и рационально использовать различные ресурсы, которые дает человечеству лес.

Выделим, что на данный момент в нашей стране главной и довольно значимой является такая задача как, грамотная, полноценная и структурированная защита всех существующих в стране лесных регионов. На основании имеющейся статистики Дальневосточный Федеральный округ имеет в себе 43 процента от общей массы в Российской Федерации разнообразных лесных ресурсов, в связи с этим он требует отдельного внимания и грамотной защиты от государства и общества в целом [2].

Основными проблемами Дальневосточного Федерального региона являются сильное загрязнение всех существующих в нем лесов, неграмотная, а также незаконная вырубка лесов, воздействие различных природных как катастроф, так и разнообразных техногенных происшествий. Указанные нами факторы сильно влияют на сокращение существующего в России, а также имеющего большую ценность и значимость для страны лесного фонда. При этом государству страны следует понимать, что сокращение лесного фонда ведет к уменьшению и уничтожению на планете биологическому разнообразию.

Изучая разнообразные регионы, которые находятся в России, на Дальнем Востоке в таком направлении, как лесные массивы, следует определить порядок по наиболее обширным территориям. На первом месте в данном регионе находится юг Якутии, после нее по обширности территорий следует Хабаровский край, а следом за ним можно отметить Приморский край. Грамотная, полноценная и структурированная система по охране всех существующих лесных массивов на рассматриваемом нами округе имеет большое значение еще потому, что данный округ имеет 
довольно большой спрос на поставку дерева от различных, находящихся рядом с ним стран [4].

Отметим, что Китай довольно часто заказывает поставки на древесину из Дальневосточного федерального округа. При этом на практике часто иностранные контрагенты решают обратиться за поставками древесины к лицам, которые в полной мере добывают данный материал совершено незаконным путем, потому что для иностранных контрагентов главное это получение древесина[1].

В современное время в первую очередь государству следует создать именно правовую защиту всего существующего в стране лесного фонда. На основании российского законодательства предусмотрено наказание за незаконную добычу дерева, которое отражено в статье 260 Уголовного кодекса Российской Федерации.

Незаконная порубка леса - это рубка различных деревьев, а также кустарников, разнообразных лиан, рубка леса по ордену, который был выдан с нарушением определенных правил, кроме этого рубка, выполняемая не на том участке или же выходя за имеющиеся у него границы, вырубка иных пород, лиан и кустарников, которые запрещены к рубке [5].

Отметим, что лицо, которое совершило определенное деяние, а именно своими действиями смогло нанести определенный вред ценным лесным массивам, понесет наказание. На основании действующего российского законодательство наказание за такой поступок установлено в статье 261 Уголовного кодекса Российской Федерации. На Дальнем востоке статьи 260 и 261 Уголовного кодекса Российской Федерации являются в полной мере актуальными, так как там происходит большое количество преступлений, которые имеют связь с существующими лесными массивами. К таким преступлениям на Дальнем Востоке относятся многочисленные и злонамеренные поджоги лесов, а также незаконная вырубка лесных массивов в достаточно больших количествах.

М.А. Васильева в своих работах писала, что на основании проведенных исследований можно отметить, что уже более десяти лет, как в разнообразных регионах нашей страны становится намного меньше различных преступлений в отношении лесных массивов. При этом исследователь отмечал, что в Дальневосточном Федеральном округе количество преступлений в отношении лесных массивов, наоборот, на постоянной основе увеличивается [1].

На основании данного фактора, все существующие в России правоохранительные органы в полной мере обязаны проводить необходимые профилактические мероприятия, чтобы предотвратить преступления в отношении имеющихся лесных массивов в стране. Помимо этого данные уполномоченные органы обязаны более тщательно подходить к раскрытию и полноценному расследованию данной категории преступлений [4].
Главные проблемы заключаются в том, что рассматриваемые леса находятся довольно далеко от Центрального Федерального округа, а кроме этого имеется проблема по не разработанности различных способов инвентаризации имеющихся лесов в Дальневосточном Федеральном округе. Еще одним минусом являются довольно обширные территории, которые густо покрыты лесами, потому что компетентные органы в полной мере не имеют возможности осуществлять требуемый контроль за всей существующей площадью в целом. В связи с этим появляются определенные «слепые» зоны, которые используют браконьеры для незаконной вырубки лесов.

Многие исследователи и ученые нашей страны считают, что определенная система, а именно система дистанционного мониторинга поможет решить данную проблему. Помимо данного фактора, отметим, что предлагаемая система сможет полноценно и значительно повысить, а также сделать имеющееся качество по грамотной и своевременной охране всех лесных массивов намного лучше. При этом дистанционный мониторинг даст значительную возможность сократить время, которое тратят правоохранительные органы на раскрытие данной категории преступлений [3].

На данный момент правительство Российской Федерации уже создало и применило на большинстве регионов такой акт, как «Прогноз научно-технологического развития Российской Федерации на период до 2030 года». Данный акт помог в полной мере создать и внедрить определенную и ценную систему по полноценному определению всей оценки имеющегося на данный момент состояния в стране лесов. Кроме этого он дал возможность внедрить различные и значимые возможности мониторинга. Выделим, что мониторинг помогает субъектам своевременно и качественно предупредить разнообразные проблемы и катастрофы, носящие природный и техногенный характер. Введение мониторинга помогает бороться с многочисленными преступлениями, которые касаются незаконной вырубки лесных массивов в стране [5].

Самый первый запуск рассматриваемых систем был реализован в 2005 году, тогда он охватил только небольшое количество субъектов страны, а именно их было 7. После пришествия определенного времени, было выявлено, что эксперимент является достаточно удачным, так как он помог решить ряд значимых для страны проблем. К таким проблемам следует относить разнообразные экологические проблемы, значимые для страны проблемы экономического характера, и проблемы связанные с вырубкой лесных массивов, как незаконной, так и неграмотной. После этого в 2013 году в данную программу вступили еще несколько регионов, и их общее число составило 24 субъекта. На данный момент в России система дистанционного мониторинга охватывает примерно около 75 процентов всех существующих в стране земель с лесными массивами [2]. 
Эффективность системы дистанционного мониторинга доказывается при помощи произошедших изменений в отношении лесных массивов в Российской Федерации, а также сокращению преступлений в данном направлении. Выделим, что благодаря рассматриваемой системе можно быстро и качественно среагировать на будущее, то есть совершаемое в данный момент преступление в сфере лесного фонда страны, кроме этого имеется возможность осуществлять полноценный контроль всех лесных фондов субъектов, которые участвуют в программе и контролировать законную вырубку леса.

При анализе данных можно увидеть, что система оправдала ожидания, а также ее дальнейшее развитие будет способствовать уменьшению преступности в отношении лесных массивов. На данный момент субъекты, в которых ввели рассматриваемую нами систему, а именно дистанционный мониторинг, были отмечены улучшения в незаконной вырубке леса, а именно нарушение лесного законодательства достаточно уменьшилось, примерно на 30 процентов нарушений стало меньше[1].

Подводя итог, следует выделить, что существующий лесной фонд в РФ является достаточно значимым и сложно восстанавливаемы, так как на это потребуются десятки лет. При этом большая часть всех существующих в России запасов лесных массивов располагаются в Дальневосточном Федеральном округе. Поэтому следует скорейшим образом устранить все разнообразные вероятности по хищению данных ресурсов или же их намеренному повреждению. Кроме этого следует наладить полностью стабильную систему по полноценной охране лесов при помощи увеличения имеющегося в данный момент состава всех правоохранительных органов в рассматриваемой нами области.
Помимо данного фактора необходимо ввести во всех субъектах систему дистанционного мониторинга, которая в полной мере дает возможность быстро и качественно среагировать на разнообразные проблемы в направлении лесных массивов страны. Довольно значимым считается разработка и принятие конкретного акта, в котором будут полностью прописаны все необходимые зоны Дальневосточного федерального округа, потому что он является и представляет для страны большое значение в сфере лесопокрытой площади. Такой акт дал бы возможность в полной мере обратить все необходимое внимание на рассматриваемый регион различных государственных органов страны, а также помогло бы предотвратить большое количество разнообразных преступлений в Дальневосточном Федеральном округе, связанных с незаконной вырубкой леса.

\section{СПИСОК ОСПОЛЬЗОВАННОЙ} ЛИТЕРАТУРЫ

1.Анисимов, А. П. Экологическое право / А.П. Анисимов, А.Я. Рыженков, А.Е. Черноморец. М.: Юрайт. 2017. С. 182.

2.Боголюбов, С. А. Правовые основы природопользования и охраны окружающей среды: учебник и практикум для академического бакалавриата / С. А. Боголюбов, Е. А. Позднякова. 3-е изд., перераб. и доп. М.: Издательство Юрайт, 2018. C. 429.

3.Дубовик, О.Л. Современное экологическое право в России и за рубежом / О.Л. Дубовик. М.: Институт научной информации по общественным наукам (ИНИОН) РАН. 2018. С. 222.

4.Исмаилова, Э. Ю. Практикум по курсу «Экологическое право» / Э.Ю. Исмаилова. М.: ЮрИнфоР-МГУ. 2018. С. 208.

5.Сборник нормативных правовых актов по экологическому праву. М.: Щит-М. 2016. С. 290. 